\title{
Powder Diffractometer
}

National Cancer Institute

\section{Source}

National Cancer Institute. Powder Diffractometer. NCI Thesaurus. Code C78855.

An instrument that detects the diffraction of high energy radiation by a crystalline specimen. 